\title{
Effect and safety of topical application of tranexamic acid to reduce perioperative blood loss in elderly patients with intertrochanteric fracture undergoing PFNA
}

\section{Huiping Wei}

Department of Orthopaedics, Nanchuan People' Hospital of Chongqing Medical University

\section{Qiuping Xiao}

Nanchuan people's hospital of chongqing medical university

Jianfeng He

Department of Orthopaedics, Nanchuan People' Hospital of Chongqing Medical University

\section{Tianji Huang}

The First Affiliated Hospital of Chongqing Medical University

\section{Wantang Xu}

Nanchuan people's hospital of chongqing medical university

\section{Siping Xian}

Nanchuan people's hospital of chongqing medical university

Menghong Xia ( $\square$ XMH_721218@163.com )

Nanchuan People' Hospital of Chongqing Medical University

\section{Research article}

Keywords: Tranexamic acid, Bleeding, Intertrochanteric fracture, Proximal femoral nail anti-rotation

Posted Date: October 14th, 2020

DOI: https://doi.org/10.21203/rs.2.21728/v2

License: (c) (i) This work is licensed under a Creative Commons Attribution 4.0 International License. Read Full License 


\section{Abstract}

Background: The specific method and dose of tranexamic acid (TXA) topically applied for intertrochanteric fractures have not been well established. The aim of this study is to investigate the efficacy and safety of TXA topically administered via our protocol for perioperative bleeding management in elderly patients with intertrochanteric fractures who underwent proximal femoral nail anti-rotation (PFNA).

Methods: A retrospective comparative analysis was performed. The TXA group was composed of 82 patients with topical use of TXA, and the control group was composed of 82 patients without TXA use during the PFNA procedure. Intraoperative, total and hidden amounts of blood loss, drainage volumes, postoperative blood transfusion volumes and complications were compared between the two groups.

Results: The intraoperative, total and hidden amounts of blood loss and the drainage volumes were significantly lower in the TXA group than in the control group $(P=0.012, P<0.01, P<0.01, P=0.014$, respectively). The volume and rate of blood transfusion in the TXA group were significantly lower than those in the control group $(P<0.01)$. There were no significant differences in complications between the two groups $(P>0.05)$.

Conclusion: Topical application of TXA offers an effective and safe option for reducing perioperative blood loss and transfusion in elderly patients with intertrochanteric fractures undergoing PFNA.

\section{Background}

With the rapid increase in the aged population, hip fractures increase rapidly in elderly people and cause serious public health and social problems[1]. Intertrochanteric fractures represent one of the major types of hip fractures, and the 1-year mortality rate after intertrochanteric fractures is reported to be approximately 25\%[2]. Proximal femoral nail anti-rotation (PFNA) has become a routine fixation method for treating senile intertrochanteric fractures with the advantages of being minimally invasive, being a simple operation and having limited intraoperative blood loss[3,4]. Compared to those with femoral neck fractures, patients with intertrochanteric fractures incur hidden blood loss and thus more often require blood transfusion[5]. Excessive postoperative bleeding causes the need for blood transfusion, which is accompanied by risks of hypersensitivity, haemolytic reactions, cardiovascular dysfunction, infectious diseases and rejection[6,7].

Tranexamic acid (TXA), an antifibrinolytic agent that can help improve coagulation function by inhibiting the degradation of fibrin, has been confirmed to reduce blood loss and transfusion requirements in hip and knee arthroplasty[8,9]. Considering that serious systemic side effects following intravenous TXA exposure are quite rare but do exist[10], topical application of TXA has attracted increasing attention and has been confirmed to reduce postoperative blood loss and blood transfusion requirements safely in patients undergoing hip arthroplasty[11,12]. 
For patients with intertrochanteric fractures who have a high risk of bleeding, especially elderly patients, the current literature contains little information about the effects of topical application of TXA on surgical outcomes after PFNA in this population. This retrospective study was conducted to evaluate the efficacy and safety of the topical application of TXA in elderly patients with intertrochanteric fractures undergoing PFNA.

\section{Methods}

Population

From August 2015 to August 2019, patients with intertrochanteric fractures undergoing PFNA (short) were retrospectively enrolled in this study. Before February 2018, patients with PFNA were not treated with TXA. After February 2018, all the patients with PFNA were treated with topical TXA. The inclusion criteria were (1) age $\geq 70$ years at the time of injury; (2) a confirmed diagnosis of intertrochanteric fractures classified according to AO type by X-ray or CT; and (3) eligibility for intertrochanteric fracture surgery using the PFNA procedure, as determined by the senior orthopaedic surgeon. The exclusion criteria were (1) allergy to TXA or low-molecular-weight heparin; (2) old, multiple or pathological fractures; (3) severe dysfunction of the heart, lung, liver, or kidney or coagulation dysfunction; (4) anticoagulant therapy such as antiplatelet drugs or warfarin before the operation; (5) recent or ongoing thromboembolic events including deep venous thrombosis, pulmonary embolism, arterial thrombosis, cerebral thrombosis, or stroke; and (6) follow-up of less than 1 month. A total of 218 patients were enrolled, 82 patients were administered topical TXA (study group), and 136 patients were not administered topical TXA during PFNA.

Intraoperative and postoperative procedures

All the patients underwent a standard surgical procedure by a single senior surgeon who specialized in hip and trauma surgery and had 8 years of experience. All patients received spinal or general anaesthesia. In the study group, the wound was bathed in $3 \mathrm{~g} / 100 \mathrm{ml}$ TXA solution for 5 min after greater trochanter exposure and before wound closure. For all patients, one drain was placed in the wound. The drain was clamped for $6 \mathrm{~h}$ and then released. The limb pneumatic pump was used for all patients on the first day after the operation (pneumatic pump treatment should be stopped if lower extremity deep vein thrombosis occurs after surgery). All patients received standard thromboprophylaxis with low-molecularweight heparin from the second day after admission to $24 \mathrm{~h}$ prior to the operation and for $12 \mathrm{~h}$ after the operation. The drain was removed when the drainage volume was $<20 \mathrm{ml}$. When patients' haemoglobin $(\mathrm{Hb})$ concentration was $<70 \mathrm{~g} / \mathrm{L}$, allogeneic blood transfusion was administered. Routine follow-up visits were scheduled at $1,3,6$ and 12 months postoperatively.

Data collection

Data were collected from medical records. Demographic and clinical characteristic data included age, sex, height, weight, and time from injury to surgery; AO type of fracture, American Society of 
Anesthesiologists (ASA) score and anaesthesia method; and preoperative $\mathrm{Hb}$ and haematocrit (Hct) levels. The intraoperative and postoperative clinical data included the operation time and intraoperative blood loss (IBL); postoperative $\mathrm{Hb}$ and Hct levels; postoperative coagulation indicators including prothrombin time (PT), international normalized ratio (INR), activated partial thromboplastin time (APTT) and D-dimer; postoperative blood loss (PBL), which was evaluated by the drainage volume; and transfusion volume. Postoperative complications included deep venous thrombosis and pulmonary embolism; wound haematoma and deep or superficial infection; myocardial infarction; and cerebrovascular accidents. Mortality and readmission rates one month after discharge were also collected.

Calculation methods

Blood loss was determined on the basis of millilitres. IBL=weight of surgical sponges+volume of blood in suction canisters-the volume of irrigation fluids. PBL was evaluated by wound drainage. The Hb levels in the blood were measured preoperatively and on postoperative day 1 (POD1) and 3 (POD3). Total blood loss $(\mathrm{TBL})=$ patient's blood volume $(\mathrm{PBV}) \times\left(\right.$ Hctpre-Hctpod3)/Hct ${ }_{\text {ave }}[13] . \mathrm{PBV}=\mathrm{k} 1 \times$ height $(\mathrm{m})^{3}+\mathrm{k} 2 \times$ weight $(\mathrm{kg})+\mathrm{k} 3(\mathrm{k} 1=0.3669, \mathrm{k} 2=0.03219$, and $\mathrm{k} 3=0.6041$ for men; $\mathrm{k} 1=0.3561, \mathrm{k} 2=0.03308$, and $\mathrm{k} 3=0.1833$ for women)[14]; $\mathrm{Hct}_{\text {pre }}$ =the preoperative Hct level; $\mathrm{Hct}_{\text {pod3 }}=$ the Hct level on postoperative day $3 ;$ Hct $_{\text {ave }}=$ the average of the $\mathrm{Hct}_{\text {pre }}$ and $\mathrm{Hct}_{\text {pod3 }}$. Hidden blood loss $(\mathrm{HBL})=\mathrm{TBL}-\mathrm{IBL}-\mathrm{PBL}+$ transfusion.

Statistical methods

To minimize selection bias, propensity score matching was performed prior to analysis. All patients in the study group ( $n=82)$ were included in the final analysis and matched with patients who did not receive topical TXA (control group, $n=82$ ), as shown in Fig. 1 . Due to the propensity matching process, the groups did not differ significantly in terms of age, sex, height, weight, time from injury to surgery, AO type of fracture, ASA score, anaesthesia method, or preoperative $\mathrm{Hb}$ and Hct level (Table 1). Once the two groups of patients were matched, further statistical analyses were conducted. Numerical data are presented as the mean \pm standard deviation (mean $\pm S D$ ) and were compared with independent t-tests. Categorical data were compared with chi-square and Fisher's exact tests. $\mathrm{P}<0.05$ was considered statistically significant. SPSS 23.0 statistical software (Chicago, IL) was used to analyse the data in this study.

\section{Results}

The operation time in the study group was recorded minus $10 \mathrm{~min}$ because there were two five-minute wait times for the topical use of TXA in the study group. Finally, no significant intergroup differences were observed in the operation time (Table 2).

The study group had significantly less IBL $(121.58 \pm 71.86$ vs $168.29 \pm 98.16 \mathrm{~mL}, \mathrm{P}=0.012), \mathrm{TBL}$ ( $566.87 \pm 186.23$ vs $813.65 \pm 293.36 \mathrm{~mL}, P<0.01)$, drainage $(112.32 \pm 57.86$ vs $202.38 \pm 76.61 \mathrm{~mL}, P=0.014)$, and $\mathrm{HBL}(447.16 \pm 187.39$ vs $652.65 \pm 271.43 \mathrm{~mL}, \mathrm{P}<0.01)$ than the control group. The levels of $\mathrm{Hb}$ and $\mathrm{Hct}$ on postoperative day 1 were apparently higher in the study group than in the control group $(99.23 \pm 22.31$ 
vs $86.76 \pm 17.88 \mathrm{~g} / \mathrm{L}, \mathrm{P}=0.039 ; 29.15 \pm 3.16$ vs $27.42 \pm 3.84 \%, \mathrm{P}=0.027)$. However, on postoperative day 3 , no significant intergroup differences were observed in the $\mathrm{Hb}$ or Hct levels. During the hospital stay, the study group had a significantly lower transfusion volume (103.64 \pm 72.35 vs $213.48 \pm 88.41 \mathrm{~mL}, P<0.01)$ and transfusion rate $(14.63$ vs $25.61 \%, P<0.01)$ than the control group (Table 2$)$.

To assess the effect of TXA on the perioperative coagulation function, the data regarding the perioperative PT, INR, APTT and D-dimer level were analysed, and there were no statistically significant differences between the two groups (Fig. 2).

There were no significant differences in deep venous thrombosis, pulmonary embolism, wound haematoma, deep or superficial infection, myocardial infarction, cerebrovascular accident, mortality or readmission one month after discharge in the two groups (Table 3).

\section{Discussion}

Intertrochanteric fractures represent a major type of hip fracture that incurs substantial blood loss because there is a large amount of muscle insertion involved around this region, and a large bone surface area is available for blood loss in extracapsular fractures[15]. Particularly for elderly and frail patients who receive surgical treatment (most of these patients have anaemia), massive blood loss usually results in blood transfusion and a high risk of perioperative morbidity and mortality[16,17]. TXA has been reported to reduce surgical blood loss effectively and safely[18] and improve perioperative care in patients undergoing hip arthroplasty[11]. However, the data regarding its use in intertrochanteric fractures with PFNA, especially topical applications, are limited. Therefore, in the present study, we sought to determine whether topical application of TXA would reduce perioperative blood loss effectively and safely.

TXA is a synthetic amino acid analogue that can reduce the need for blood loss and transfusion due to its characteristic of plasminogen inhibition[11,12]. In selective knee and hip arthroplasty, the efficacy of TXA in reducing blood loss is generally accepted[19]. Some studies have focused on intravenous TXA for bleeding management in intertrochanteric fracture patients with PFNA. The results have indicated that intravenous use of TXA perioperatively can reduce total and hidden blood loss[20]. We first reported the effects of topical application of TXA in intertrochanteric fracture patients with PFNA. Our data showed that the TBL was reduced by $30 \%$ (from 813 to $566 \mathrm{~mL}$ ) and the HBL was reduced by $31 \%$ (from 652 to $447 \mathrm{~mL}$ ) after topical treatment with TXA during surgery. Moreover, we also confirmed an obvious reduction in IBL $(28 \%$, from 168 to $121 \mathrm{~mL})$ and drainage $(45 \%$, from 202 to $112 \mathrm{~mL})$ in the study group. Our data indicate that topical application of TXA has equivalent or even better effects for controlling perioperative bleeding than intravenous TXA in intertrochanteric fracture patients with PFNA.

Only two studies have reported the effects of topical application of TXA in intertrochanteric fracture patients with short cephalomedullary nails, dynamic hip screws and barrel plates but not with PFNA. Drakos et al reported a randomized prospective trial in 200 intertrochanteric fracture patients treated with short cephalomedullary nails[21]. The patients received $3 \mathrm{~g}$ TXA in the subfascial plane and around the 
fracture site before wound closure. Their data showed a $43 \%$ reduction in transfusion requirements in the TXA group. Virani SR et al reported a randomized prospective trial in 137 intertrochanteric fracture patients treated with dynamic hip screws and barrel plates[22]. The patients received subfascial and intramuscular infiltration of $2 \mathrm{~g}$ TXA before wound closure. However, they found no significant differences in transfusion between the TXA and control groups. These differences could be due to the different internal fixation methods, mode of application and dosage of TXA. Our results are similar to those of Drakos et al[21] who showed a $42.6 \%$ reduction in transfusion requirements in the study group. Considering that administration before wound closure does not reduce intraoperative bleeding, we soaked the wound with TXA for 5 min after greater trochanter exposure and before wound closure. We confirmed an obvious reduction in IBL $(28 \%$, from 168 to $121 \mathrm{~mL})$. We found that a similar approach was used recently for bleeding control in acetabular fractures, and the approach was confirmed to effectively reduce $\mathrm{IBL}[23]$.

The potential increased risk of thromboembolic events is the primary concern when administering TXA because TXA promotes thrombosis by inhibiting fibrinolysis and increases thrombus mass[24]. Topical application has little or no systemic exposure of TXA, and it can potentially avoid the complications of intravenous TXA. Our data showed that there were no significant differences in deep venous thrombosis, pulmonary embolism, myocardial infarction or cerebrovascular accidents. These results were consistent with recent studies on the topical application of TXA in hip fractures[21,22,25]. Coagulation function was also evaluated, and perioperative PT, INR, APTT and D-dimer levels were not significantly different between the two groups in this study. One patient in each group was readmitted one month after discharge for wound infection and cured with antibiotics and dressing changes. We also found that topical use of TXA did not increase the risk of wound complications or mortality.

To the best of our knowledge, this is the first study on the topical application of TXA in intertrochanteric fracture patients with PFNA, and propensity score matching was used to minimize selection bias. However, this was a retrospective study with a small number of patients. In addition, the optimal dosing and timing of TXA administration

are still controversial. Therefore, further prospective randomized controlled trials with larger sample sizes and different doses and times of TXA administration are warranted to confirm our findings.

\section{Conclusions}

This study demonstrated that topical application of TXA could effectively and safely reduce postoperative blood loss and decrease transfusion in senile intertrochanteric fracture patients undergoing PFNA.

\section{Declarations}

Ethics approval and consent to participate 
This retrospective study was approved by the Ethics Committee of Nanchuan People's Hospital of Chongqing Medical University(YLJS-202025) and performed in line with the Declaration of Helsinki international ethical guidelines for studies involving human subjects. Written informed consent was obtained prospectively from all patients prior to surgery.

Consent to publish

Written consent for publication were obtained from all individual participants included in the study.

Availability of data and materials

The datasets used and analysed during the current study are available from the corresponding author on reasonable request.

Competing interests

The authors declare that they have no competing interests.

Funding

There are no sponsors for this study.

Authors' contributions

HPW and QPX Data collection, Data analysis, Writing the paper. JFH, TJH and WTX Data collection, Data analysis, Writing the paper. SPX Performed the experiments. MHX conception and Design of study, Principal Investigators. And all authors have read and approved the manuscript.

Acknowledgements

We would like to thank Dr. Gang Luo from Department of Orthopaedics, The first affiliated hospital of Chongqing medical university for providing guidance for this study.

\section{Abbreviations}

PFNA: Proximate femoral nail annotation; TXA: Tranexamic acid; Hb: Hemoglobin; ASA: American society of anesthesiologists; Hct: Hematocrit; IBL: Intraoperative blood loss; PT: Prothrombin time; INR: International normalized ratio; APTT: Activated partial thromboplastin time; PBL: Postoperative blood loss; POD: Postoperative days; TBL: Total blood loss; PBV: Patient's blood volume; HBL: Hidden blood loss

\section{References}


1. Cooper C, Cole ZA, Holroyd CR, Earl SC, Harvey NC, Dennison EM, Melton LJ, Cummings SR, Kanis JA; IOF CSA Working Group on Fracture Epidemiology. Secular trends in the incidence of hip and other osteoporotic fractures. Osteoporos Int. 2011;22(5):1277-88. https://doi.org/10.1007/s00198011-1601-6.

2. Davidson CW, Merrilees MJ, Wilkinson TJ, McKie JS, Gilchrist NL. Hip fracture mortality and morbidity-can we do better? NZ Med J. 2001;114(1136):329-32.

3. Nie B, Wu D, Yang Z, Liu Q. Comparison of intramedullary fixation and arthroplasty for the treatment of intertrochanteric hip fractures in the elderly: A meta-analysis. Medicine (Baltimore). 2017;96(27):e7446. https://doi.org/10.1097/MD.0000000000007446.

4. Queally JM, Harris E, Handoll HH, Parker MJ. Intramedullary nails for extracapsular hip fractures in adults. Cochrane Database Syst Rev. 2014;(9):CD004961. https://doi.org/10.1002/14651858.CD004961.

5. Zhu Q, Yu C, Chen X, Xu X, Chen Y, Liu C, Lin P. Efficacy and Safety of Tranexamic Acid for Blood Salvage in Intertrochanteric Fracture Surgery: A Meta-Analysis. Clin Appl Thromb Hemost. 2018;24(8):1189-98. https://doi.org/10.1177/1076029618783258.

6. Kumar A. Perioperative management of anemia: limits of blood transfusion and alternatives to it. Cleve Clin J Med. 2009;Suppl4:S112-8. https://doi.org/10.3949/ccjm.76.s4.18.

7. Newman ET, Watters TS, Lewis JS, Jennings JM, Wellman SS, Attarian DE, Grant SA, Green CL, Vail TP, Bolognesi MP. Impact of perioperative allogeneic and autologous blood transfusion on acute wound infection following total knee and total hip arthroplasty. J Bone Joint Surg Am. 2014;96(4):279-84. https://doi.org/10.2106/JBJS.L.01041.

8. DiBlasi JF, Smith RP, Garavaglia J, Quedado J, Frye BM, Dietz MJ. Comparing Cost, Efficacy, and Safety of Intravenous and Topical Tranexamic Acid in Total Hip and Knee Arthroplasty. Am J Orthop. 2016;45:E439-43.

9. Xie J, Ma J, Yao H, Yue C, Pei F. Multiple Boluses of Intravenous Tranexamic Acid to Reduce Hidden Blood Loss After Primary Total Knee Arthroplasty Without Tourniquet: A Randomized Clinical Trial. J Arthroplasty. 2016;31(11):2458-64. https://doi.org/10.1016/j.arth.2016.04.034.

10. Wang S, Gao X, An Y. Topical versus intravenous tranexamic acid in total knee arthroplasty: a metaanalysis of randomized controlled trials. Int Orthop. 2017;41(4):739-48. https://doi.org/10.1007/s00264-016-3296-y.

11. Kang JS, Moon KH, Kim BS, Yang SJ. Topical administration of tranexamic acid in hip arthroplasty. Int Orthop. 2017;41(2):259-63. https://doi.org/10.1007/s00264-016-3195-2.

12. Sanz-Reig J, Mas Martinez J, Verdu Román C, Morales Santias M, Martínez Gimenez E, Bustamante Suarez de Puga D. Matched cohort study of topical tranexamic acid in cementless primary total hip replacement. Eur J Orthop Surg Traumatol. 2018;28(7):1335-9. https://doi.org/10.1007/s00590-0182192-0.

13. Gross JB. Estimating allowable blood loss: corrected for dilution. Anesthesiology. 1983;58(3):277-80. 
14. Nadler SB, Hidalgo JH, Bloch T. Prediction of blood volume in normal human adults. Surgery. 1962;51(2):224-32.

15. Dillon MF, Collins D, Rice J, Murphy PG, Nicholson P, Mac Elwaine J. Preoperative characteristics identify patients with hip fractures at risk of transfusion. Clin Orthop Relat Res. 2005;439:201-6. https://doi.org/10.1097/01.blo.0000173253.59827.7b.

16. Ktistakis I, Giannoudis V, Giannoudis PV. Anticoagulation therapy and proximal femoral fracture treatment: An update. EFORT Open Rev. 2017;1(8):310-5. https://doi.org/10.1302/20585241.1.160034.

17. Moran CG, Wenn RT, Sikand M, Taylor AM. Early mortality after hip fracture: is delay before surgery important? J Bone Joint Surg Am. 2005;87(3):483-9. https://doi.org/10.2106/JBJS.D.01796.

18. Ker K, Edwards P, Perel P, Shakur H, Roberts I. Effect of tranexamic acid on surgical bleeding: systematic review and cumulative meta-analysis. BMJ. 2012;344:e3054. https://doi.org/10.1136/bmj.e3054.

19. Chen Y, Chen Z, Cui S, Li Z, Yuan Z. Topical versus systemic tranexamic acid after total knee and hip arthroplasty: a meta analysis of randomized controlled trials. Medicine (Baltimore). 2016;95(41):e4656. https://doi.org/10.1097/MD.0000000000004656.

20. Zhou XD, Zhang Y, Jiang LF, Zhang JJ, Zhou D, Wu LD, Huang Y, Xu NW. Efficacy and Safety of Tranexamic Acid in Intertrochanteric Fractures: A Single-Blind Randomized Controlled Trial. Orthop Surg. 2019;11(4):635-42. https://doi.org/10.1111/os.12511.

21. Drakos A, Raoulis V, Karatzios K, Doxariotis N, Kontogeorgakos V, Malizos K, Varitimidis SE. Efficacy of local administration of Tranexamic Acid for blood salvage in patients undergoing intertrochanteric fracture surgery. J Orthop Trauma. 2016;30(8):409-14. https://doi.org/10.1097/BOT.0000000000000577.

22. Virani SR, Dahapute AA, Panda I, Bava SS. Role of Local Infiltration of Tranexamic Acid in Reducing Blood Loss in Peritrochanteric Fracture Surgery in the Elderly Population. Malays Orthop J. 2016;10(3):26-30. https://doi.org/10.5704/MOJ.1611.013.

23. Sandeep Kashyap, Shweta Mahajan, Mukand Lal. Effects of topical tranexamic acid during open reduction and internal fixation of acetabular fractures: A retrospective study. Acta Orthop Traumatol Turc. 2019;53(3):175-9. https://doi.org/10.1016/j.aott.2019.03.006.

24. Sperzel $M$, Huetter J. Evaluation of aprotinin and tranexamic acid in different in vitro and in vivo models of fibrinolysis, coagulation and thrombus formation. J Thromb Haemost. 2007;5(10):2113-8. https://doi.org/10.1111/j.1538-7836.2007.02717.x

25. Kwak DK, Jang CY, Kim DH, Rhyu SH, Hwang JH, Yoo JH. Topical tranexamic acid in elderly patients with femoral neck fractures treated with hemiarthroplasty: efficacy and safety? - a case-control study. BMC Musculoskelet Disord. 2019;20(1):228. https://doi.org/10.1186/s12891-019-2615-z.

\section{Tables}


Table 1

Demographic and preoperative data in both groups.

\begin{tabular}{|c|c|c|c|}
\hline & Control group & Study group & $\mathbf{P}$ \\
\hline & $(n=82)$ & $(n=82)$ & \\
\hline Age(year) & $79.81(6.12)$ & $80.53(5.84)$ & 0.288 \\
\hline Gender(Male/Female) & $27 / 55$ & $26 / 56$ & 0.836 \\
\hline Height(m) & $1.63(0.12)$ & 1.62(0.09) & 0.174 \\
\hline Weight(kg) & $59.11(11.65)$ & 61.82(12.14) & 0.136 \\
\hline $\mathrm{BMI}\left(\mathrm{kg} / \mathrm{m}^{2}\right)$ & $22.56(4.03)$ & $22.72(3.63)$ & 0.328 \\
\hline Time from injury to surgery(day) & $3.84(1.91)$ & $4.12(2.12)$ & 0.131 \\
\hline AO type of fracture $(31 \mathrm{~A} 1 / 31 \mathrm{~A} 2 / 31$ & $40 / 27 / 15$ & $37 / 29 / 16$ & 0.211 \\
\hline ASA score(II/III/IV) & $3 / 76 / 3$ & $2 / 75 / 5$ & 0.266 \\
\hline Anesthesia(Spina/General) & $37 / 45$ & $36 / 46$ & 0.714 \\
\hline Preoperative $\mathrm{Hb}(\mathrm{g} / \mathrm{L})$ & 108.34(13.45) & $111.28(14.21)$ & 0.082 \\
\hline Preoperative Hct(\%) & $33.32(4.48)$ & $33.96(3.98)$ & 0.344 \\
\hline $\begin{array}{l}\text { BMI: body mass index } \\
\text { Hb: hemoglobin; Hct: }\end{array}$ & san society of & anesthesiolo & \\
\hline
\end{tabular}

Table 2

Comparison of perioperative data between the two groups.

\begin{tabular}{|llll|}
\hline & Control group & Study group & P \\
\hline Operation time(min) & $76.54(19.23)$ & $74.87(22.72)$ & 0.589 \\
\hline IBL(mL) & $168.29(98.16)$ & $121.58(71.86)$ & 0.012 \\
|Hb POD1(g/L) & $86.76(17.88)$ & $99.23(22.31)$ & 0.039 \\
Hb POD3(g/L) & $85.14(19.21)$ & $92.58(24.45)$ & 0.281 \\
Hct POD1(\%) & $27.42(3.84)$ & $29.15(3.16)$ & 0.027 \\
Hct POD3(\%) & $26.98(4.12)$ & $28.41(3.66)$ & 0.082 \\
Transfusion rate(n, \%) & $21(25.61 \%)$ & $12(14.63 \%)$ & $<0.01$ \\
Transfusion volume(mL) & $213.48(88.41)$ & $103.64(72.35)$ & $<0.01$ \\
|TBL(mL) & $813.65(293.36)$ & $566.87(186.23)$ & $<0.01$ \\
Drainage(mL) & $202.38(76.61)$ & $112.32(57.86)$ & 0.014 \\
HBL(mL) & $652.65(271.43)$ & $447.16(187.39)$ & $<0.01$ \\
\hline IBL: intraoperative blood loss; Hb: hemoglobin; Hct: hematocrit; & \\
\hline POD1/3: postoperative days 1/3; TBL: total blood loss; HBL: hidden blood loss \\
\hline
\end{tabular}

Table 3

Postoperative complications in both groups.

\begin{tabular}{|llll|}
\hline \multicolumn{4}{|c|}{ Control groupStudy groupP } \\
\hline Deep venous thrombosis $(\mathrm{n}, \%)$ & $18(21.95 \%)$ & $16(19.51 \%)$ & 0.521 \\
Pulmonary embolism(n, \%) & $1(1.22 \%)$ & $2(2.44 \%)$ & 0.753 \\
Wound haematoma(n, \%) & $3(3.66 \%)$ & $3(3.66 \%)$ & 0.851 \\
Wound infection(n, \%) & $3(3.66 \%)$ & $2(2.44 \%)$ & 0.662 \\
Myocardial infarction(n, \%) & 0 & 0 & - \\
|Cerebrovascular accident(n, \%) $1(1.22 \%)$ & 0 & 0.412 \\
Mortality(n, \%) & 0 & 0 & - \\
Readmission(n, \%) & $1(1.22 \%)$ & $1(1.22 \%)$ & 0.996 \\
\hline
\end{tabular}


Figures

Patients undergoing PFNA who meet inclusion and exclusion criteria $(\mathrm{n}=218)$

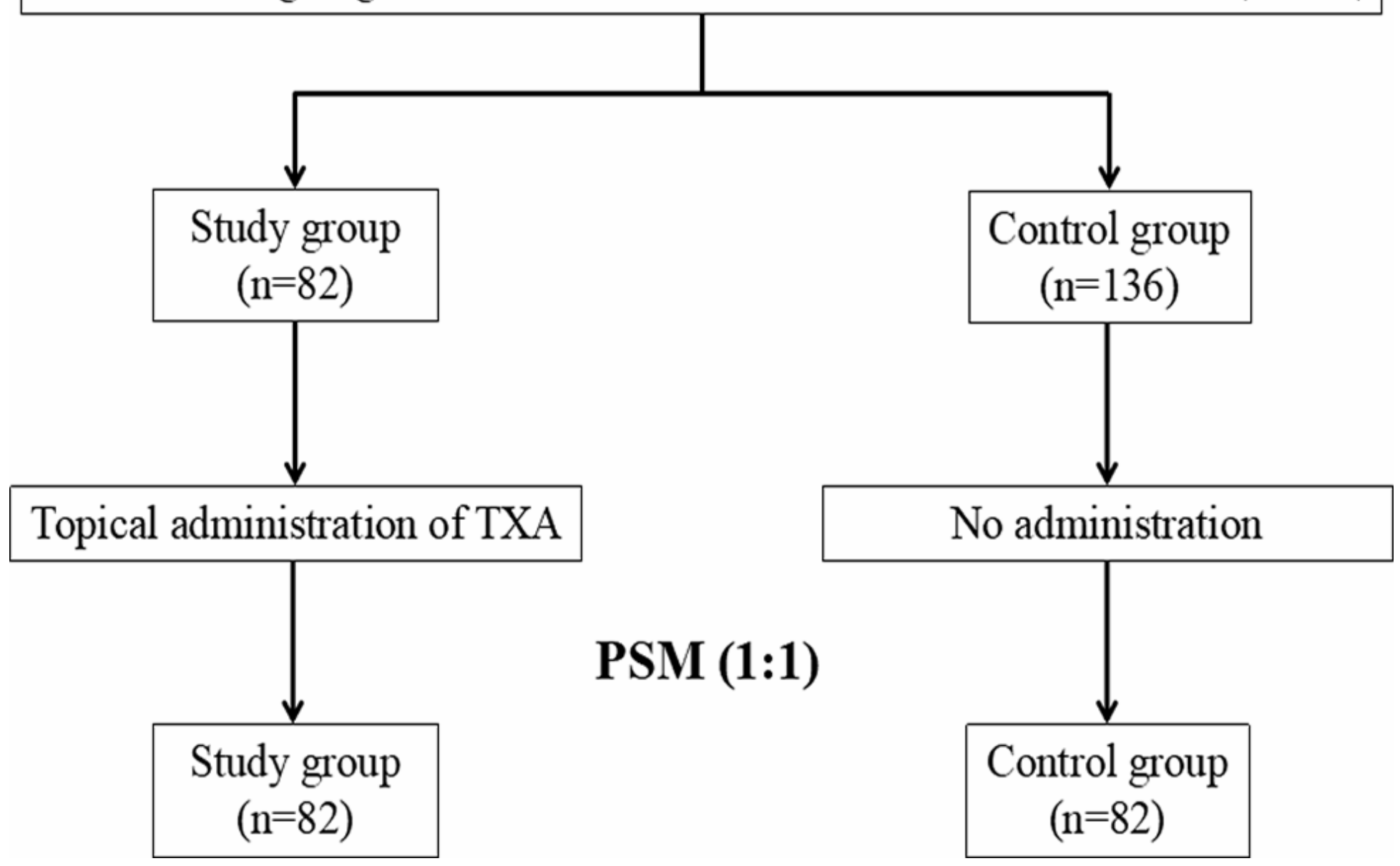

Figure 1

Flowchart demonstrating patient selection. 

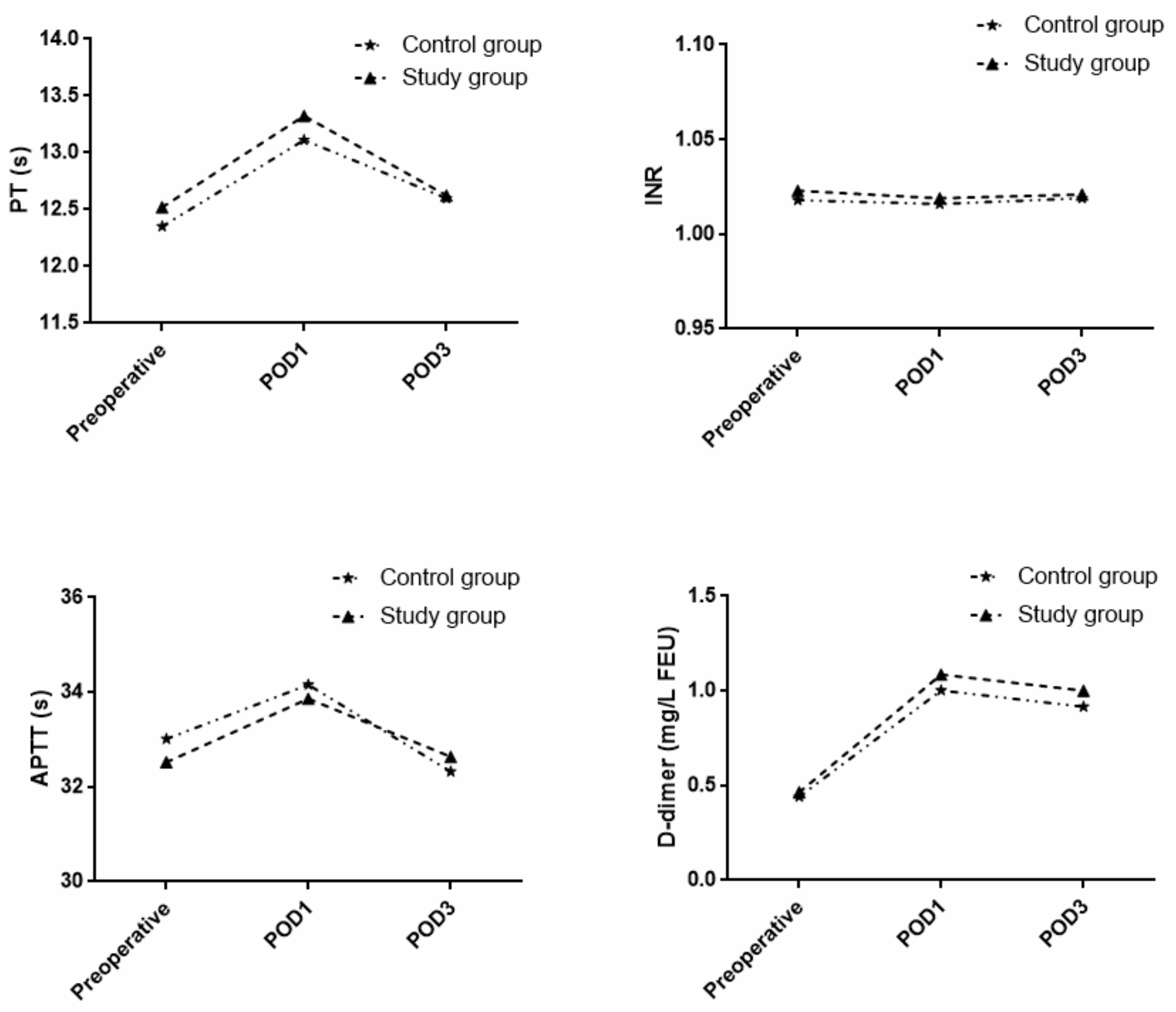

Figure 2

Comparison of perioperative coagulation function between two groups. There were not statistical significant in PT, INR, APTT and D-dimer between two groups. 